\title{
The Effect of Cold Compress on Pain Intensity Due to Arterial Sheath Removal in Patients Undergoing Coronary Angioplasty in Selected Military Hospitals
}

\author{
Alikhani. S1 \\ *Kalroozi. F² \\ Nezamzadeh. $\mathrm{M}^{3}$ \\ Pishgooie. $\mathrm{SAH}^{4}$ \\ 1- MSc in Student Emergency \\ Nursing, Faculty of Nursing, Aja \\ University of Medical Sciences, \\ Tehran, Iran. \\ 2- ( ${ }^{*}$ Corresponding Author) \\ MSc in Pediatric Nursing, \\ Instructor, Pediatric Nursing \\ Department, Faculty of Nursing, \\ Aja University of Medical \\ Sciences, Tehran, Iran. \\ Email: fkalroozi1385@yahoo.com \\ 3- MSc in Nursing, Instructor, \\ Critical Care Nursing \\ Department, Faculty of Nursing, \\ Aja University of Medical \\ Sciences, Tehran, Iran. \\ 4- Ph.D. in Nursing, Associate \\ Professor, Critical Care Nursing \\ Department, Faculty of Nursing, \\ Aja University of Medical \\ Sciences, Tehran, Iran.
}

\begin{abstract}
Introduction: Pain is a common and unpleasant complication reported by patients undergoing angioplasty following arterial sheath removal. Pain is one of the most common complications of arterial sheath removal in patients undergoing coronary artery angioplasty, which has been reported to be very unpleasant.
\end{abstract}

Objective: This study aimed to determine the effect of cold compress on pain intensity due to arterial sheath removal in patients undergoing coronary angioplasty.

Materials and Methods: The present study is a semi-experimental study consisting of 60 patients undergoing coronary artery angioplasty hospitalized in selected hospitals of Aja in the second half of 2019. The research samples were selected by convenient method and randomly divided into cold compressions $(n=30)$ and control $(n=30)$ groups. Demographic and Visual Analog Scales were used for data collection. The intervention was done using a $2 \times 2 \times 4 \mathrm{~cm}$ ice pack placed in a latex glove with a sterile gauze cover and used for 5 minutes before the the removal of sheath and there was no intervention in the control group. Data were collected in three stages before, during and after the intervention and analyzed with SPSS 23.

Results: Mean scores of pain intensity were not significantly different between the two groups before the intervention, while in comparing these two variables during the intervention, a statistically significant difference was observed between $(\mathrm{P}<0.001)$.

Discussion and Conclusion: The results showed that cold compress can be effective in reducing the pain intensity to arterial sheath removal in patients under coronary angioplasty, so it is recommended that one of nursing interventions be used in this regard.

Keywords: Angioplasty, Cold, Pain, Patient. 


\section{بررسى تأثير استفاده از كميرس سرد بر شدت درد ناشى از خروج شيت شريانى در بيماران

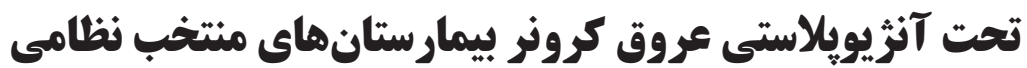

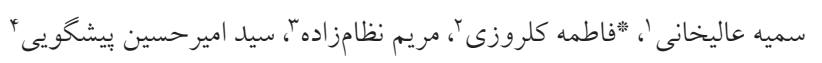

جكيده

مقدمه: درد از عوارض شايع و ناخوشايندى است كه به دنبال خروج شيت شريانى، توسط بيماران تحت آنزيويلاستى

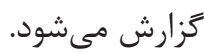

هدف: اين مطالعه با هدف تعيين تأثير استفاده از كميرس سرد بر شدت درد ناشى از خروج شيت شريانى در بيماران

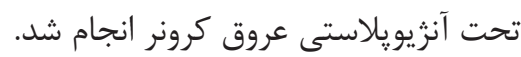

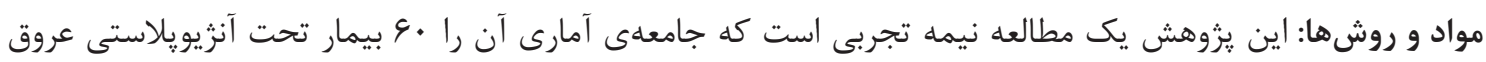

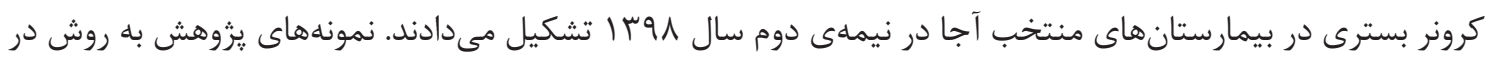

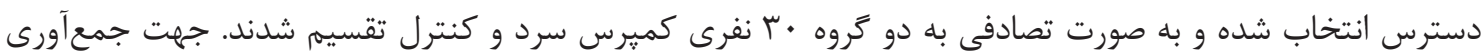

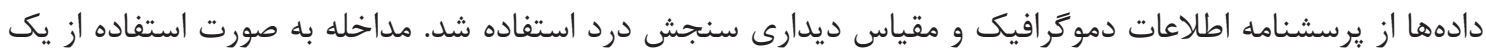

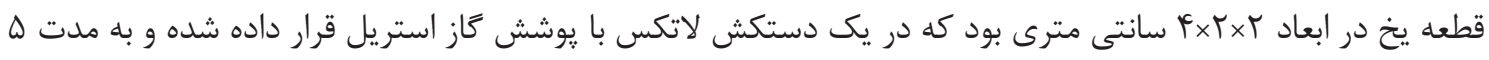

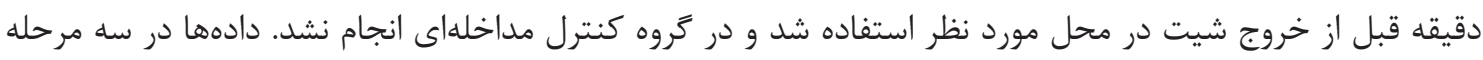

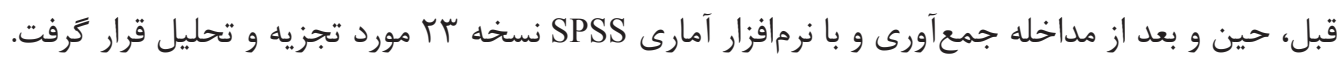

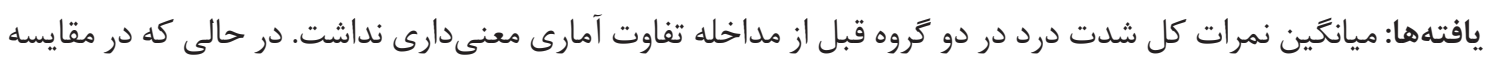

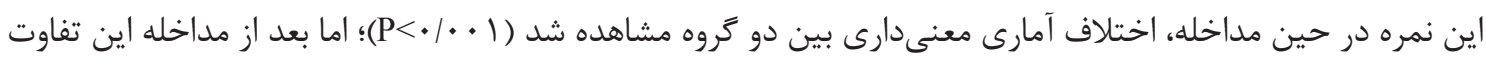

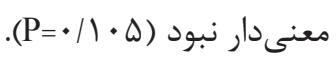

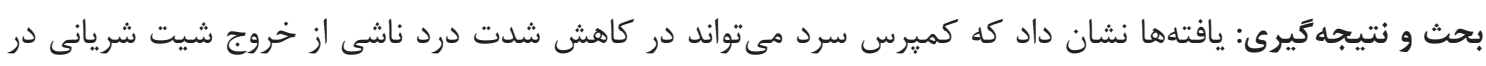

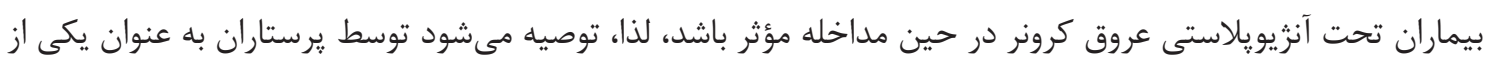
مداخلات يرستارى در اين زمينه مورد استفاده قرار كيرد. كلمات كليدى: آنزيو يلاستى، بيمار، درد، سرما.

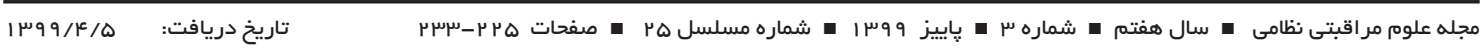
تاريخ يذيرش: تاريخ دريافت:

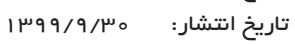

مرى و مير در سراسر دنيا محسوب مىشوند (Y). بيمارىهاى مقلمها بيمارى هاى قلبى-عروقى (Cardiovascular Disease) به كروهى مربوط به عروق كرونر، به عنوان اصلىترين علت بيمارى و ناتوانى

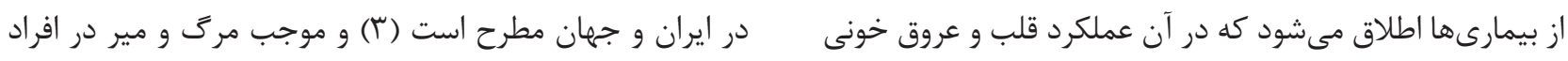

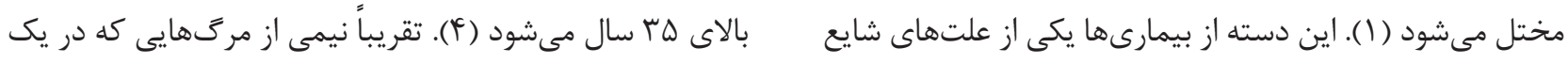


به منظور كاهش عوارض ناشى از خروج شيت شريانى روشهاى مختلفى به كار برده مىشود كه به دو دستهى دارويى ماريى مانند تجويز

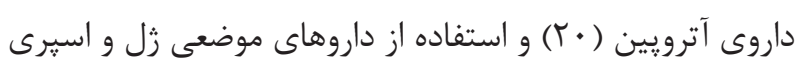

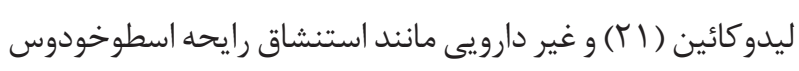

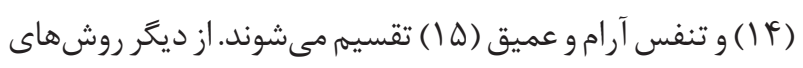

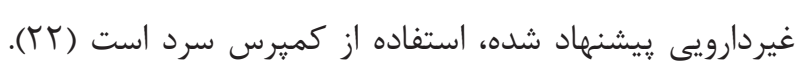

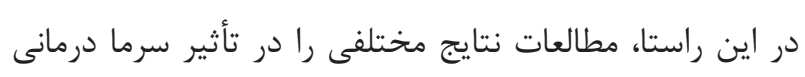

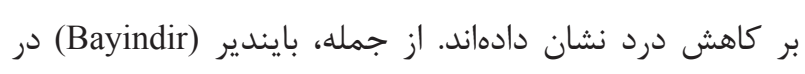
مطالعهى خود استفاده از كيسه يخ به مدت د ب د دقيقه در ناحيه

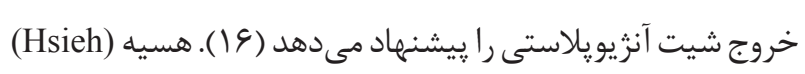
و همكاران تأثير كميرس سرد در كاهش شدت درد ناشى از خروج لولهى قفسهى سينه يس از جراحى قلب را مورد بررسى قرار دادند

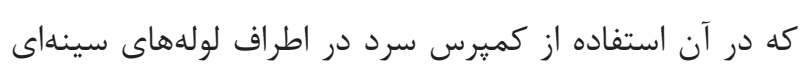

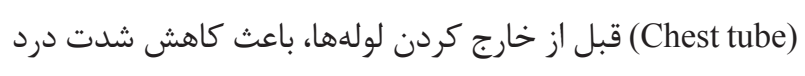

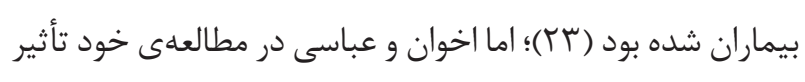

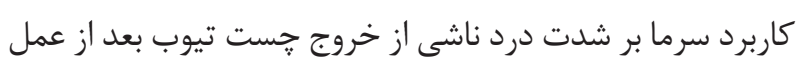

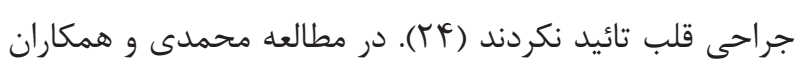

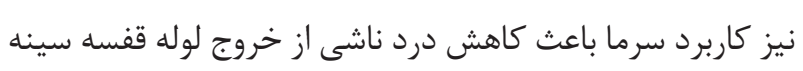

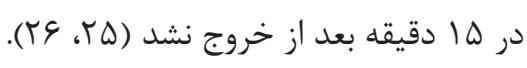

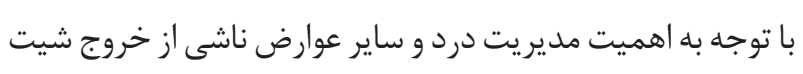

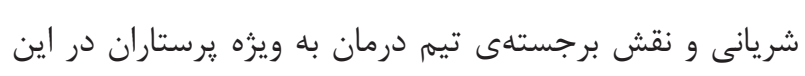

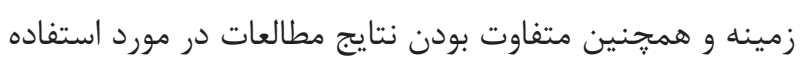

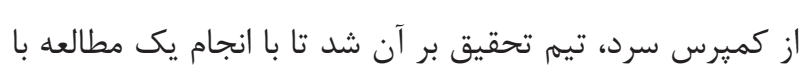

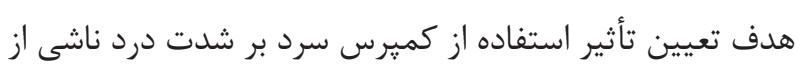
خروج شيت شريانى در بيماران تحت آنزيويلاستى عروق كرونر كامى در راستاى كمك به اين بيماران بردارد.

\section{مواد و روشها}

اين مطالعه يك مطالعهى نيمه تجربى دو كروهه مى باشد كه جامعه

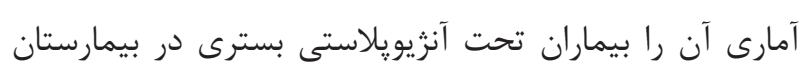

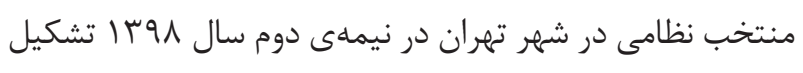

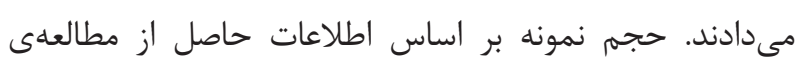
rrv

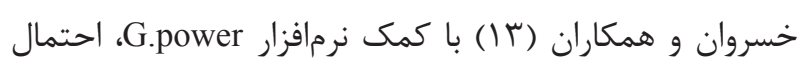

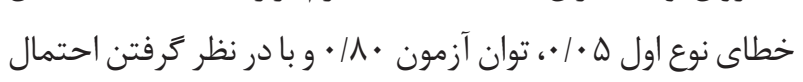

سال اتفاق مىافتد، به بيمارى قلبى - عروقى و به طور خاص به بيمارى عروق كرونر نسبت داده مىشود (ه). امروزه برحسب ميزان اختلال در عملكرد قلب، شدت و و علائم

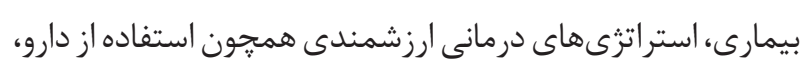

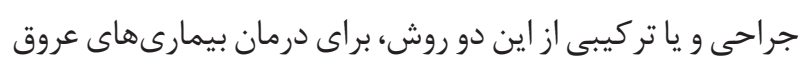

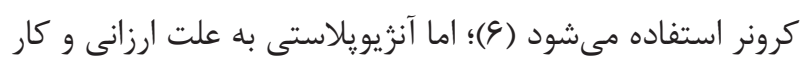

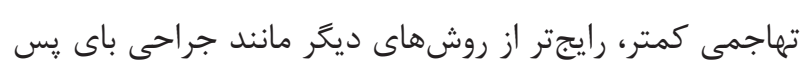

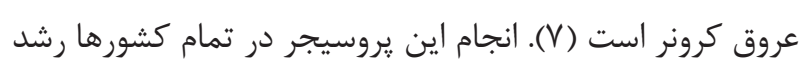

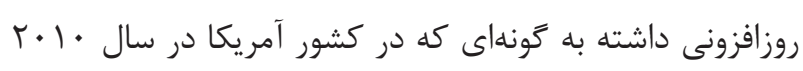

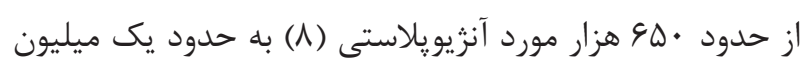

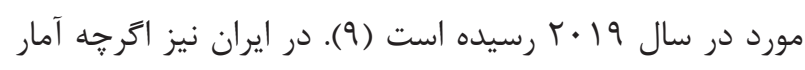
دقيقى در اين مورد در دست نيست، اما با شـيـوع روزافزون تعداد

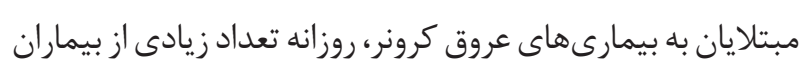
به مداخلات جراحى نياز پِيدا مى كنند (• ().

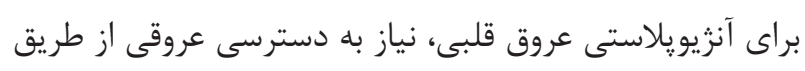

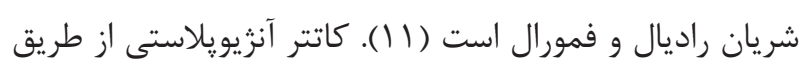

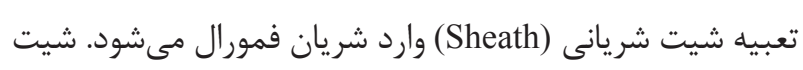

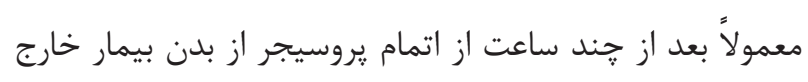

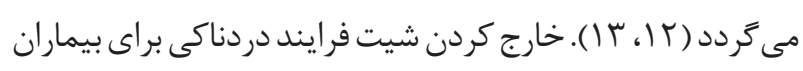

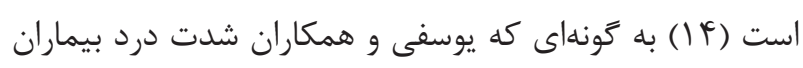

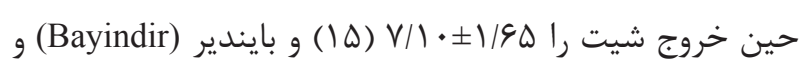

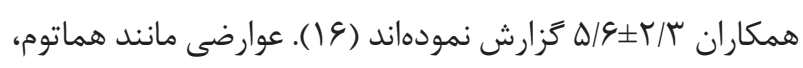
خونريزى، آنوريسم كاذب و درد به دنبال كاتتريزاسيون و تعبيه

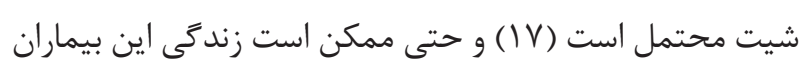
را تهديد كرده و با افزايش طول مدت بسترى بيمار، هزينه درمان

و خطر عفونتهاى بيمارستانى را نيز بالا مىبرد (1) (1).

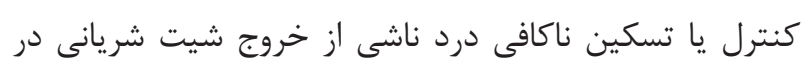

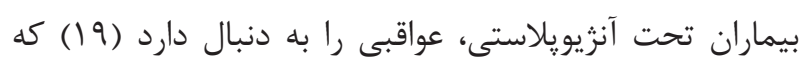

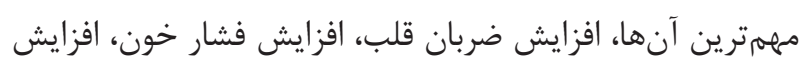

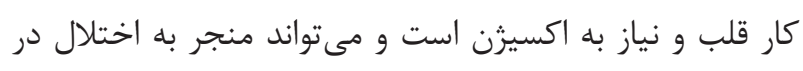
عملكرد بطن جٍ، ايسكمى ميوكارد و سكتهى قلبى تردد (ه (1).

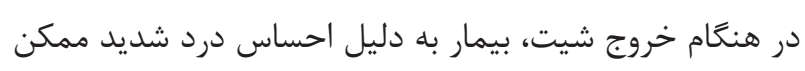

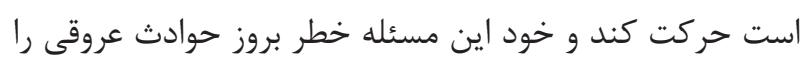
افزايش مى دهد (ب آ). 
ميزان انطباق (Goodness of Fit Index) معادل • 9 • • و ريشه دوم

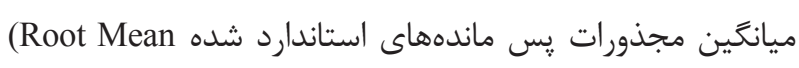
Square Error of Approximation) در اين مطالعه كه در همان بخش بسترى و بر روى تخت بيمار و

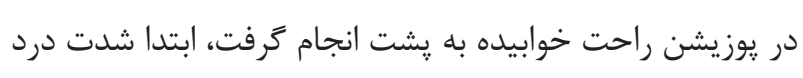

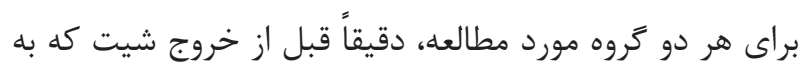

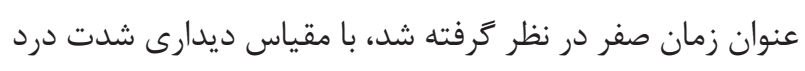

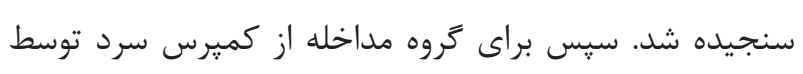
يروهشكر استفاده شد، بدين صورت كه يك قطعه يخ در در ابعاد

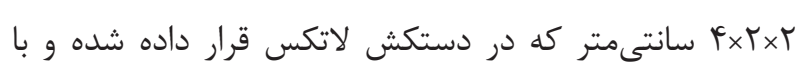

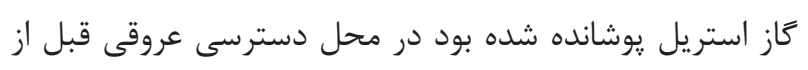
كشيدن شيت كذاشته شد. تحت شرايط استريل، شيت از محل خود، خارج شده و نبض ناحيه فمورال تا هموستاز كامل شريان

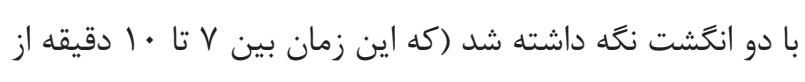

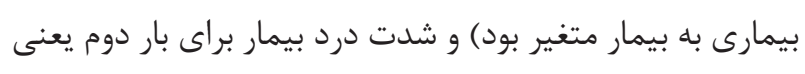

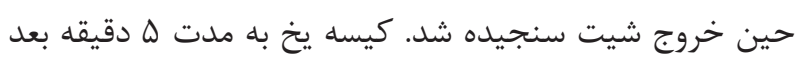

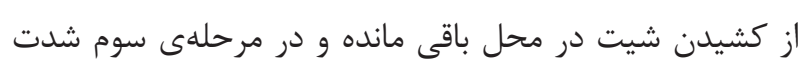

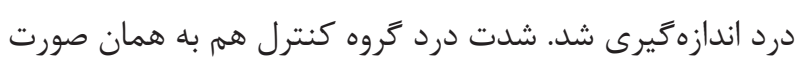

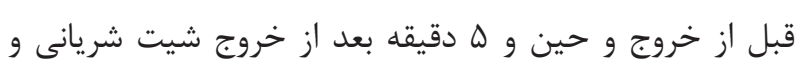

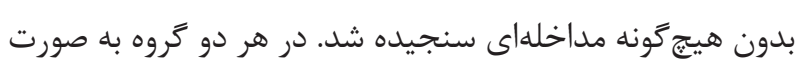

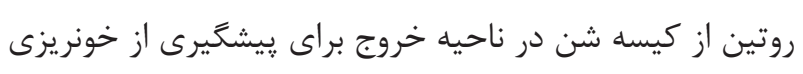

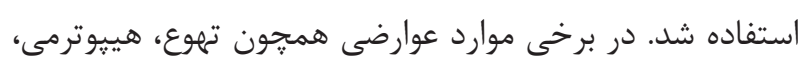

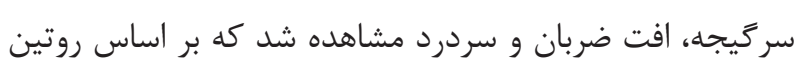

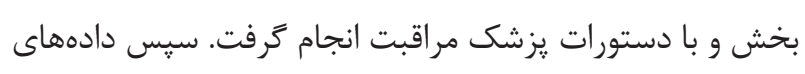

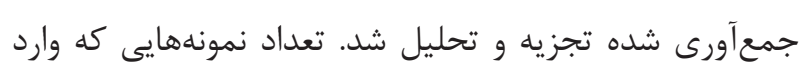

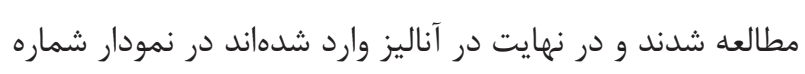
ا نشان داده شده است.

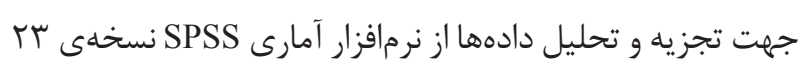
و آزمونهاى آمارى تى مستقل، آزمون دقيق فيشر و كاى اسكوئر

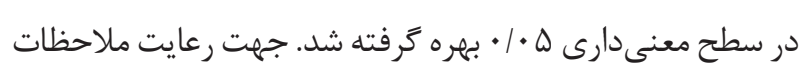

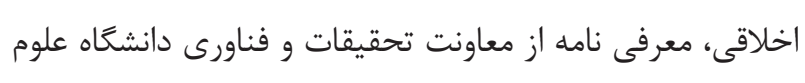

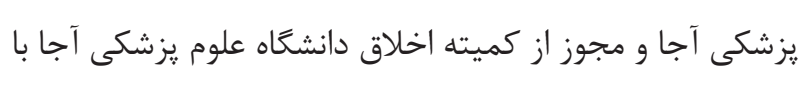

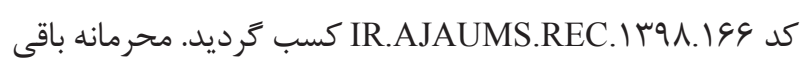
ماندن تمام مستندات مربوط به بيماران، رعايت امانت در منابع

$$
\text { ريزش • ا درصد، · س نفر در هر گروه تعيين شد. }
$$

$\mathrm{T}$ tests - Means: Difference between two independent means (two groups)

Analysis: A priori: Compute required sample size Input:

$$
\text { Tail (s) }
$$

$=$ Two

Effect size d

$\alpha$ err prob

$=\mid /$ TY II A

Power (1- $\beta$ err prob)

$=. / .1$

Allocation ratio $\mathrm{N} 2 / \mathrm{N} 1$

$=\cdot / 9$

$=1$

Output:

Noncentrality parameter $\delta$

$=Y \% .99 \Delta V Q T$ Critical t

Df

$=r / 991.99 r$

Sample size group $1=r V$

Sample size group $2=r V$

Total sample size $\quad=\Delta \uparrow$

Actual power

$=\cdot / \Lambda \cdot \vee \neg \mu \wedge \Lambda$

نمونهها بر اساس معيارهاى ورود شامل: تمايل داشتن براى شركت

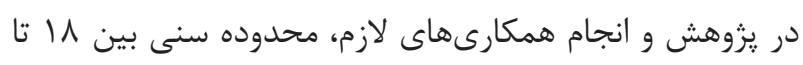

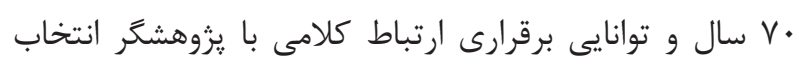
شدند. معيارهاى خروج شامل: مصرف داروهاى مخدر تجويز نشده،

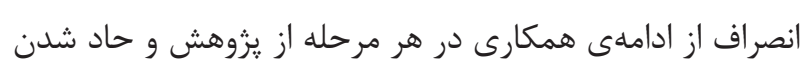

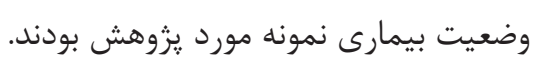

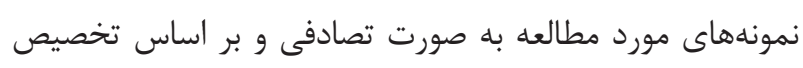

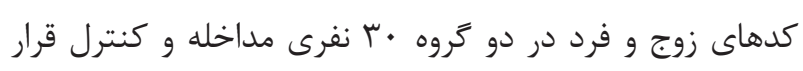

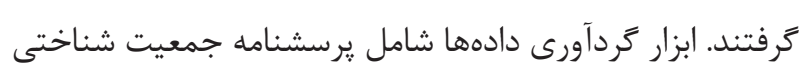
و مقياس ديدارى سنجش شدت درد (Visual Analog Scale)

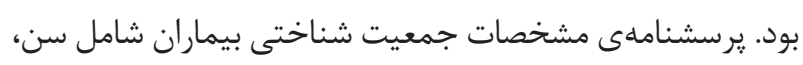
جنس، وضعيت تأهل، تحصيلات، شغل، بيمارى زمينهاى و سابقه

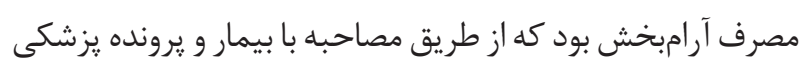

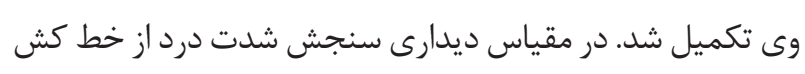

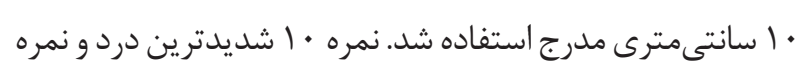

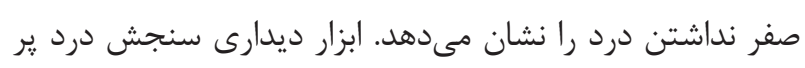
كاربردترين ابزار سنجش درد در دنيا است كه عـلاوه بر روايسى و ״ايايى تائيد شده، مهمترين خصيصه ايـن ابزار سادگى استفاده از

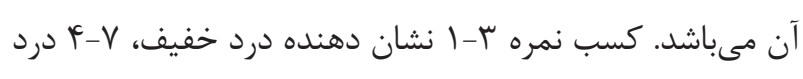

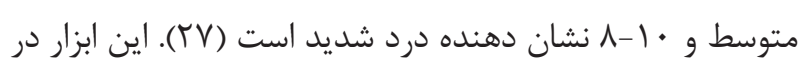

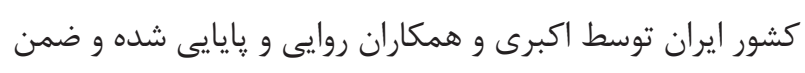

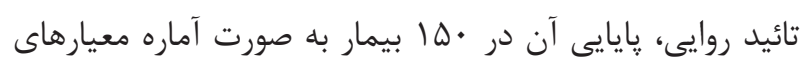




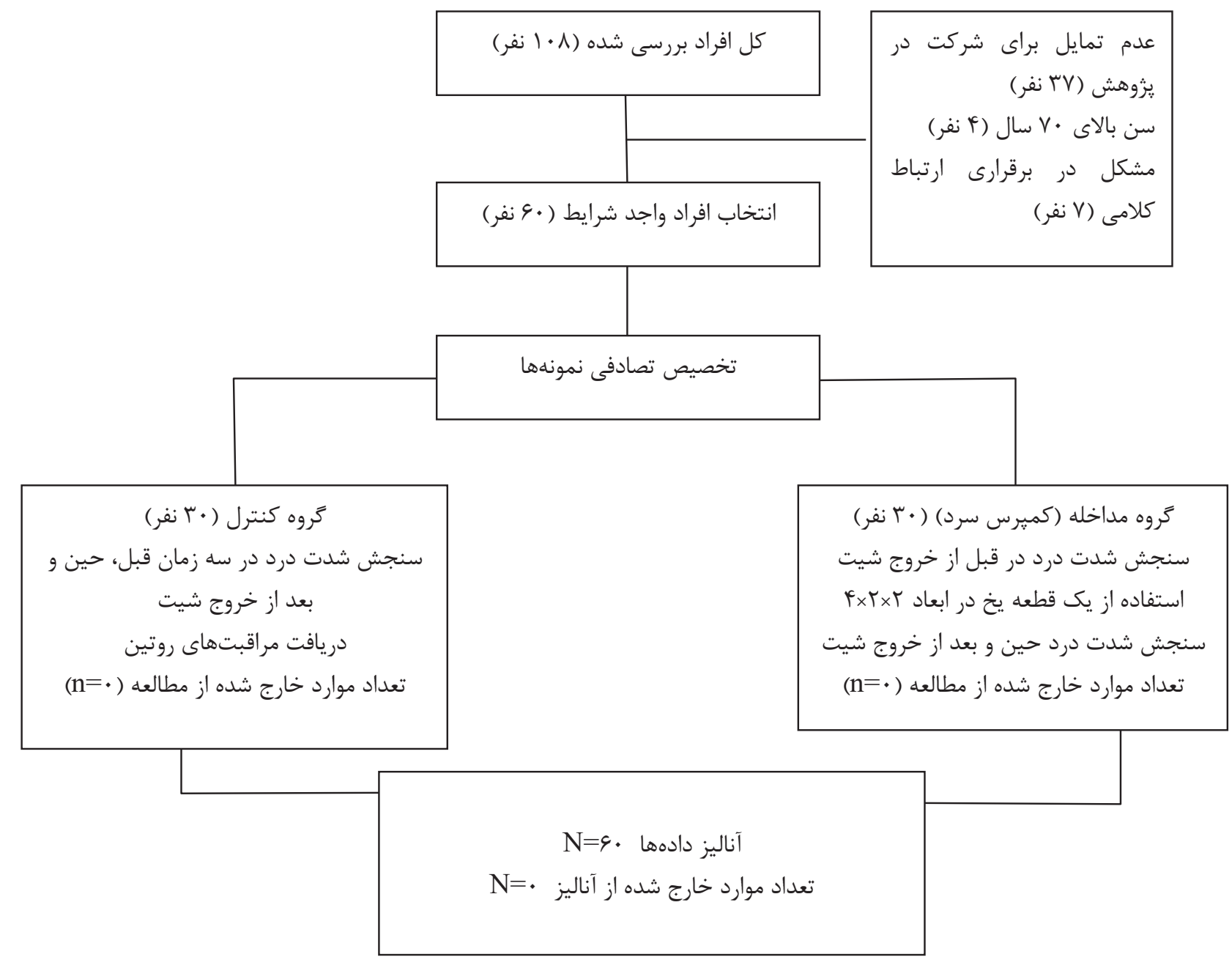

نمودار ا- نمودار كونسورت واحدهاى مورد مطالعه

گروه مداخله و كنترل از نظر متغيرهاى دموگرافيك و مصرف مسكن در F Tاعت گذشته توسط بيمار همگن بوده و تفاوت معنى دارى نداشتند (جدول ()). بر اساس هدف مطالعه، ميانگين نمرات شدت درد بيماران ارزيابى شد كه قبل از مطالعه از نظر آمارى تفاوت معنى دارى نداشتند (ه • • P>). در مقايسه ميانخين نمرات شدت درد در دو گروه حين مطالعه با استفاده از آزمون تى مستقل اختلاف آمارى معنى دارى بين دو گروه مشاهده شد درد

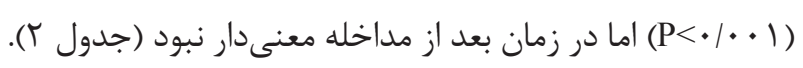

\section{بحث و نتيجه}

مطالعه حاضر با هدف تعيين تأثير استفاده از كميرس سرد بر شدت
اطلاعاتى استفاده شده، بر اساس آيين نشر COPE انجام و رعايت شد. همجنين محقق خود و اهداف يروهش را براى نمونهها معرفى كرده و يادآور شد كه شركت در مطالعه كاملاً اختيارى بوده و تأثيرى بر روند درمان آنها ندارد و اطلاعات شركت كنند محرمانه خواهد ماند و رضايت نامه آكَاهانه از تمام بيماران اخذ شد. با توجه به اينكه ناحيه فمور مورد مداخله بود، براى رعايت حريم خصوصى از ياراوان استفاده شد و طرح انطباق جنسيتى رعايت شد. همجنين قبل از هركونه مداخلهاى از يزشك معالج جهت كشيدن شيت تأييديه و مجوز كتبى دريافت شد.

\section{بافته ها}

در اين يزوهش •و نفر بيمار تحت آنزيويلاستى شركت داشتند

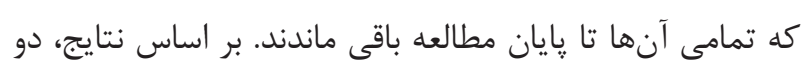


جدول ا-ويزّكى هاى جمعيت شناختى بيماران تحت آنثيو يلاستى عروق كرونر شركت كننده در مطالعه

\begin{tabular}{|c|c|c|c|c|c|}
\hline \multirow{3}{*}{ سطح معنى دارى } & \multirow{3}{*}{ آماره } & \multicolumn{2}{|c|}{ كروه } & \multirow{3}{*}{ متغير } & \\
\hline & & كنترل & كميرس سرد & & \\
\hline & & تعداد (درصد) & تعداد (درصد) & & \\
\hline \multirow{3}{*}{$\cdot|\pi| 9$} & \multirow{3}{*}{$X^{r}=r / .9 q$} & $\Delta(\mid \& / V)$ & $11(r g / V)$ & • •- آ سال & \multirow{3}{*}{ بازمى سنى "** } \\
\hline & & $I V(\Delta S / V)$ & W & 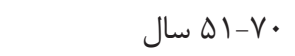 & \\
\hline & & $\Lambda(Y \& / Y)$ & $\varphi(\Delta)$ & بالاى •V سال & \\
\hline.$/ I F T$ & $\mathrm{t}=r / T / T$ & $9 r \pm 1.119$ & $\Delta 9 \pm 1 r / 9 T$ & انحراف معيار 土 ميانگَين & سن" \\
\hline \multirow{3}{*}{$\cdot / T V F$} & \multirow{3}{*}{$X^{r}=r / \Delta 91$} & $\varphi(\Delta)$ & $\Delta(\mid \& / V)$ & زيردييلم & \multirow{3}{*}{ تحصيلات *** } \\
\hline & & $10(\Delta \cdot)$ & l· $(r / r)$ & دييلم & \\
\hline & & $q(r \cdot)$ & $10(\Delta \cdot)$ & دانشخاهى & \\
\hline \multirow{3}{*}{$\cdot / V \Delta V$} & \multirow{3}{*}{$X^{r}=\cdot \mid \Delta \Delta \varphi$} & 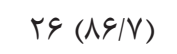 & $T F(\Lambda \cdot)$ & متأهل & \multirow{3}{*}{ وضعيت تأهل ****** } \\
\hline & & $r(\Delta)$ & $f(\mid r / \mu)$ & مجرد & \\
\hline & & $1(r / \mu)$ & $r(\varepsilon / V)$ & ساير & \\
\hline \multirow{3}{*}{$\cdot \mid \Lambda V Y^{c}$} & \multirow{3}{*}{$X^{r}=\cdot / r \& q$} & $19(\Delta \Gamma / \Gamma)$ & $\mid f(F \& / V)$ & نظامى & \multirow{3}{*}{ اشتغال } \\
\hline & & $\varphi(\Delta)$ & $V(T / / T)$ & غيرنظامى & \\
\hline & & $\Lambda(Y G / V)$ & $q(\Gamma \cdot)$ & ساير & \\
\hline \multirow{2}{*}{.1099} & \multirow{2}{*}{$X^{r}=\cdot 19 \mu \omega$} & IV $(\Delta S / V)$ & $r \cdot(\xi q / V)$ & مرد & \multirow{2}{*}{ جنسيت" } \\
\hline & & W & 1· & زن - ت & \\
\hline \multirow{2}{*}{$\cdot / \pi \cdot 1$} & \multirow{2}{*}{$X^{r}=1 / 999$} & $\mid r\left(Y^{F} \cdot\right)$ & IV $(\Delta \& / V)$ & بله & \multirow{2}{*}{ سابقه جراحى:"** } \\
\hline & & $1 \wedge(\varphi \cdot)$ & س & خير & \\
\hline
\end{tabular}

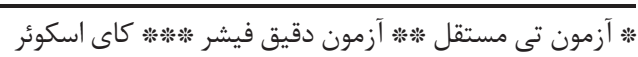

جدول r- مقايسه ميانغين و انحر اف معيار نمرات شدت درد بيماران مورد يزوهش در دو تروه مورد مطالعه در طى سه مرحله قبل، حين و بعد از مداخله

\begin{tabular}{|c|c|c|c|c|}
\hline بعد & حين & قبل & \multirow{2}{*}{ تعداد } & \multirow{2}{*}{ 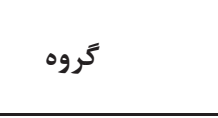 } \\
\hline انحراف معيار \ ميانگين & انحراف معيار \ ميانغين & انحراف معيار \ ميانگين & & \\
\hline$r / \Lambda \cdot \pm 1 / \cdot 9$ & $\Delta / V \Psi \pm I / T r$ & $T / 1 T \pm \cdot / \Lambda q$ & r. & كميرس سرد \\
\hline c/rr $\pm \cdot / 9 r$ & $V / T G \pm I / \Delta F$ & $4 / 19 \pm \cdot / 91$ & r. & كنترل \\
\hline $1 / 94 \lambda$ & $F / \Delta r \Delta$ &.$/ 148$ & $\mathrm{t}$ & \multirow{2}{*}{ آزمون تى مستقل } \\
\hline$\cdot 11 \cdot 0$ & $\mathrm{P}<\bullet / \cdot \cdot 1$ & - IATF & $\mathrm{p}$ & \\
\hline
\end{tabular}

بيماران تحت آنزيويلاستى عروق كرونر حين خروج شيت مؤثر

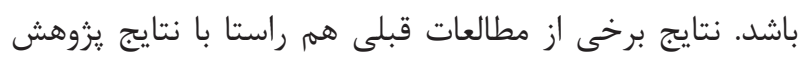
حاضر مىباشد. محمدى و همكاران يك مطالعه با هدف كاربرد سرما بر كاهش درد ناشى از خروج لوله قفسه سينه در بيماران

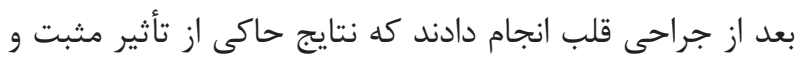
معنى دار كميرس سرد بر كاهش درد حين خروج لوله قفسه سينه
نتايج حاصل از مطالعه، ميانگين نمرات شدت درد بيماران قبل

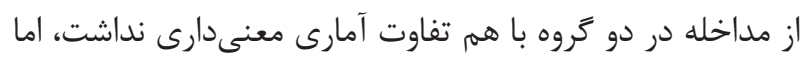

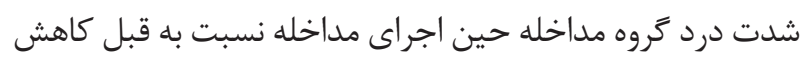

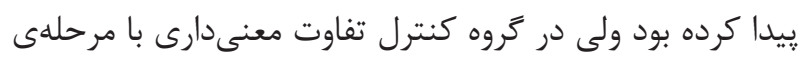

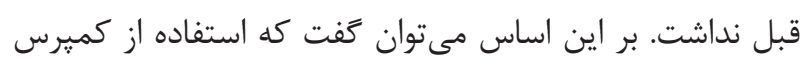

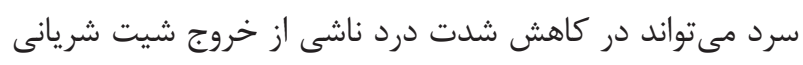


درد مؤثر بوده است. سرما با ايجاد بى حسى موضعى، كاهش ادم،

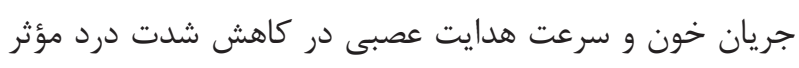

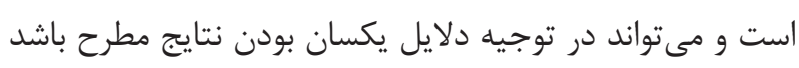

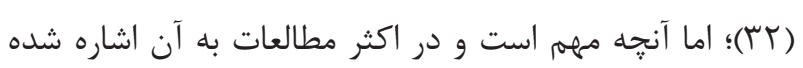

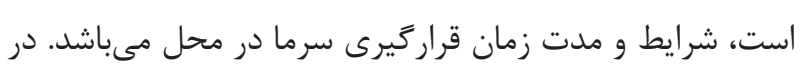

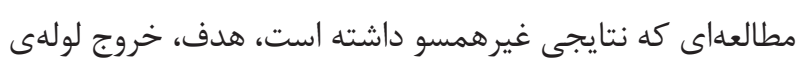
قفسه سينه بوده است كه با خروج شيت شريانى متفاوت مى باشد.

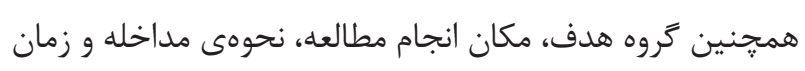

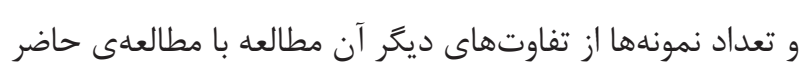
مىباشد كه مىتواند از دلايل توجيه اين ناهمسويى باشد.

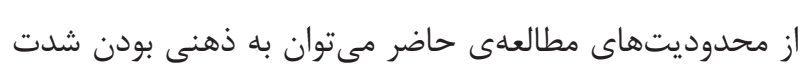

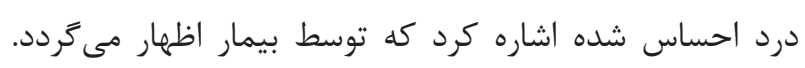
همجنين مصرف داروهاى مسكن تجويزى توسط يزشك بود كه

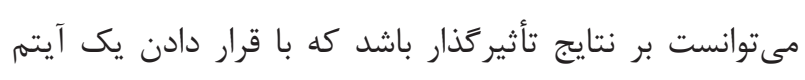
تحت عنوان مصرف مسكن در بF ساعت كذشته توسط بيمار و

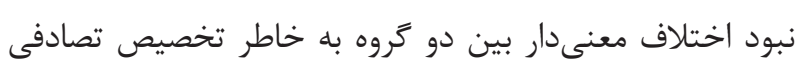
شرايط يكسان شد.

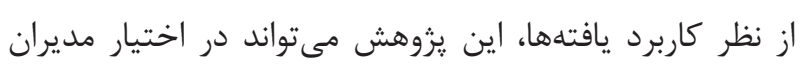

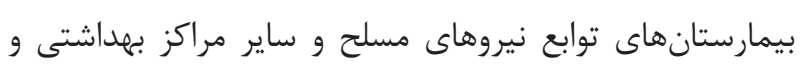

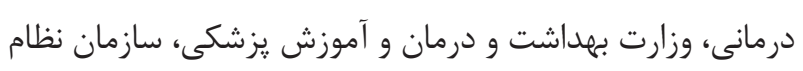

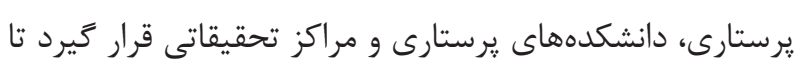

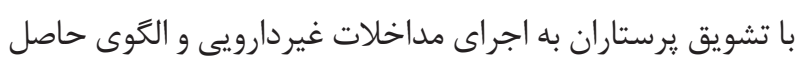

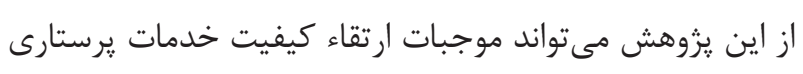

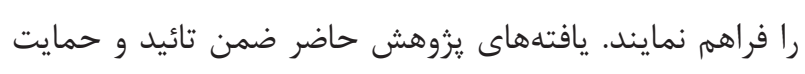

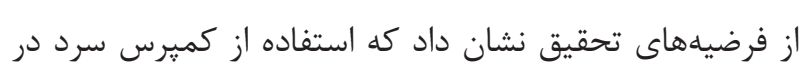

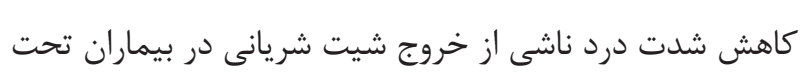

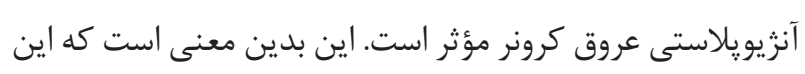

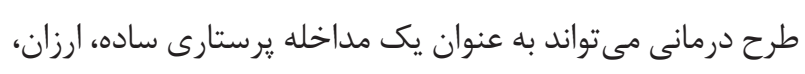
قابل اجرا و مؤثر مفيد واقع شود.

\section{تشكر و قدردانى}

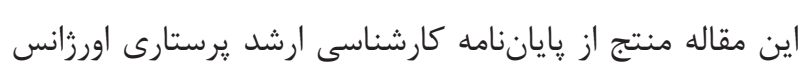

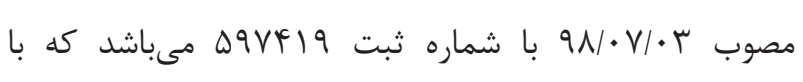
حمايتهاى مالى دانشكاه علوم يزشكى آجا به انجام رسيده است.
در بيماران بود (Whalil) (Ka) در كشور مصر يك مطالعه تحت عنوان بررسى تأثير كاربرد كيسه يخ بر كاهش درد ناشى از داز

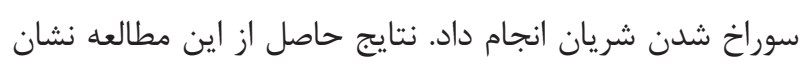

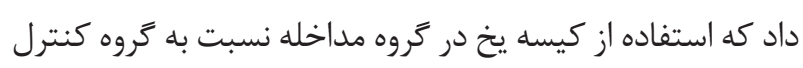

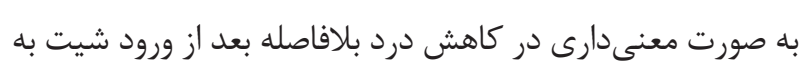
شريان كمك كننده بوده است (r (Y). بايندر (Bayındır) و همكاران

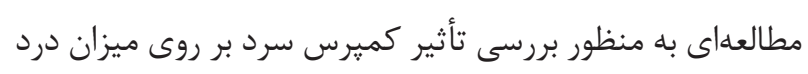

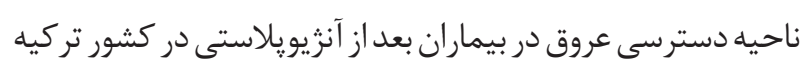

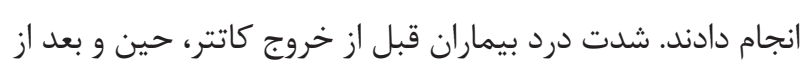

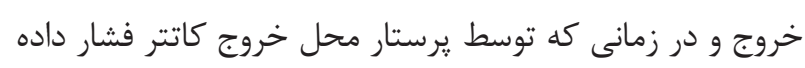

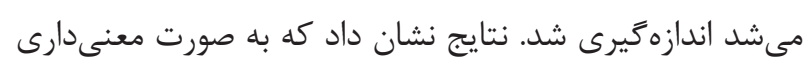
شدت درد احساس شده در گروه مداخله نسبت به كروه كنترل حين خروج كاتتر كمتر بوده است (ع) (1). عباسى تشنيزى و همكاران

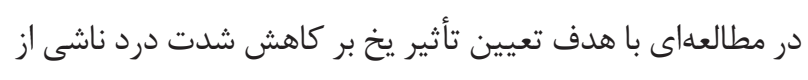

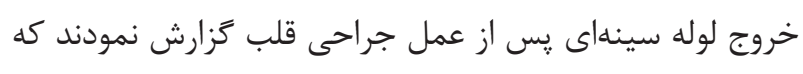

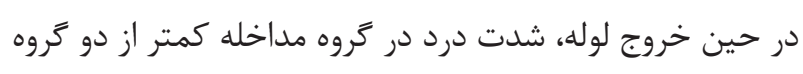

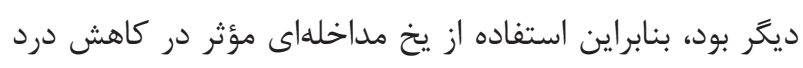

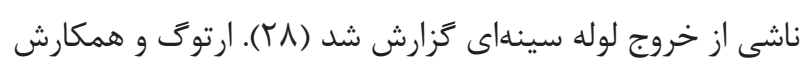
(Ertug) نتايج مطالعهى شيما (Shimaa) در كشور مصر با هدف تعيين اثربخشى كاربرد يخ بر عوارض محل دسترسى عروقى بعد از

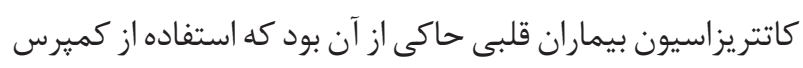

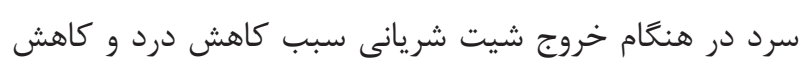
نياز بيماران به استفاده از مسكن ها مىشود ( • (ب). در همين راستا

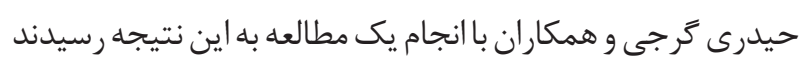

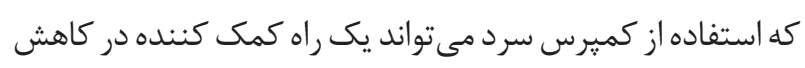
شدت درد ناشى از خروج لوله قفسه سينه در بيماران باشد ( آب).

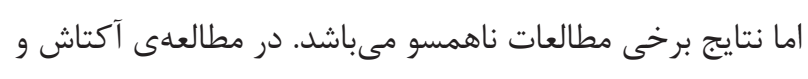

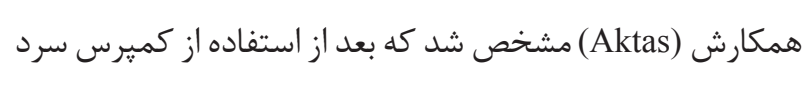

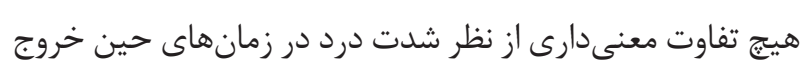

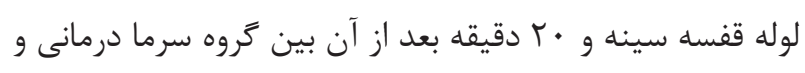

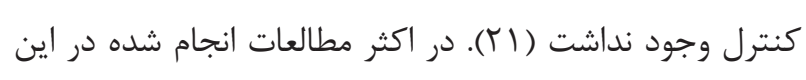
زمينه، نتايج هم سو با مطالعهى حاضر بوده و يافتهها نشان داده ندان

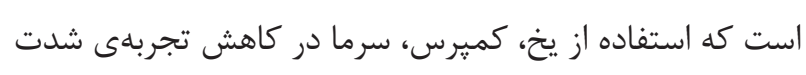




$$
\text { دراد منافع اين يزوهش هيج تضاد منافعى توسط نويسندكان اعلام نشده }
$$

\section{References}

1- Lopez AD, Adair T. Is the long-term decline in cardiovasculardisease mortality in high-income countries over? Evidence from national vital statistics. Int J Epidemiol. 2019; 48(6): 1815-23. DOI: 10.1093/ije/dyz143 PMID: 31378814

2- Darvishpour A, Javadi Pashaki N, Salari A, Taleshan Nejad M, Barari F. Comparing the Quality of Life in Patients with Cardiovascular Diseases Before and After Coronary Angioplasty. Journal of Mazandaran University of Medical Sciences. 2016; 26(137): 206-10.

3- Sabbaghgol H. Detection of coronary artery disease using C4. 5 decision tree. Journal of Health and Biomedical Informatics. 2017; 3(4): 287-99.

4- Ebrahimi K, Salarilak S, Khadem Vatan K. Determine the burden of myocardial infarction. Tehran University Medical Journal TUMS Publications. 2017; 75(3): 208-18.

5- World Health Organization ROftEPsamse. Regional office for the Eastern Mediterranean: World Health Organization; 2016. 2nd:[Available from: http://irje.tums.ac.ir/article-1-5512-fa.html.

6- Kandaswamy E, Zuo L. Recent Advances in Treatment of Coronary Artery Disease: Role of Science and Technology. Int J Mol Sci. 2018; 19(2). DOI: 10.3390/ijms19020424 PMID: 29385089

7- Norozi S, Rai A, Salimi E, Tavan H. The incidence of major cardiovascular events relied coronary vessels after angioplasty and stent types complications. Tehran University Medical Journal TUMS Publications. 2018; 75(10): 722-9.

8- Peterson JC, Allegrante JP, Pirraglia PA, Robbins L, Lane KP, Boschert KA, et al. Living with heart disease after angioplasty: A qualitative study of patients who have been successful or unsuccessful in multiple behavior change. Heart Lung. 2010; 39(2): 105-15. DOI: 10.1016/j.hrtlng.2009.06.017 PMID: 20207270

9- Research i. Over 965, 000 Angioplasties are Performed Each Year in the United States iData Research; 2020. Available from: https:// idataresearch.com.

10- Allahbakhshian A, Hasankhani H, Mohammadi E, Zamanzadeh V, Ghafari S. Second life after angioplasty: a qualitative study. Iranian Journal of Cardiovascular Nursing. 2014; 2(4): 52-63.

11- Akhavan S, Abbasi P. A different look at transradial angiography. Iranian J Cardiovasc Nurs. 2016; 5(2): 66-71.

12- Juergens CP, Lo S, French JK, Leung DY. Vaso-vagal reactions during femoral arterial sheath removal after percutaneous coronary intervention and impact on cardiac events. Int J Cardiol. 2008; 127(2): 252-4. DOI: 10.1016/j.ijcard.2007.02.059 PMID:

$$
\text { محترينوسيله نويسند مان مراتب تشكر و قدردانى خود را از مديريت }
$$

\section{0}

13- Khosravan S, Atayee P, Mazloum Shahri S, Mojtabavi S. Effect of Hugo's point massage with and without ice on vaccinationrelated pain in infants. Hayat, Journal of School of Nursing and Midwifery, Tehran University of Medical Sciences. 2018;24(1):719.

14- Pourmirzaie M, Teymouri F, Farsi Z, Rajai N, Mousavi Nejad M. The Effects of Inhaling Lavender Fragrance on Hemodynamic Indexes during Sheath Take out in Patients after Coronary Angiography in a Military Hospital. Military Caring Sciences. 2017; 4(1): 30-8. DOI: 10.29252/mcs.4.1.30

15- Yousefi Z, Rezaei K, Hoseini K. The Effect of Deep and Slow Breathing on Pain and Pain Outcomes During Arterial Sheath Removal After Undergoing Coronary Angioplasty Iranian J Cardiovasc Nurs. 2015; 4(3): 46-53.

16- Bayindir SK, Curuk GN, Oguzhan A. Effect of Ice Bag Application to Femoral Region on Pain in Patients Undergoing Percutaneous Coronary Intervention. Pain Res Manag. 2017; 2017: 6594782. DOI: 10.1155/2017/6594782 PMID: 28634432

17- Benson LM, Wunderly D, Perry B, Kabboord J, Wenk T, Birdsall B, et al. Determining best practice: comparison of three methods of femoral sheath removal after cardiac interventional procedures. Heart Lung. 2005; 34(2): 115-21. DOI: 10.1016/j. hrtlng.2004.06.011 PMID: 15761456

18- Jones T, McCutcheon H. A randomised controlled trial comparing the use of manual versus mechanical compression to obtain haemostasis following coronary angiography. Intensive \& Critical Care Nurs. 2003; 19(1): 11-20. DOI: 10.1016/s09643397(03)00005-3

19- Wensley CJ, Kent B, McAleer MB, Price SM, Stewart JT. Pain relief for the removal of femoral sheath in interventional cardiology adult patients. Cochrane Database Syst Rev. 2008(4): CD006043. DOI: 10.1002/14651858.CD006043.pub2 PMID: 18843700

20- Rama BN, Mohiuddin SM, Mooss AN, Khemani AK, Ryschon $\mathrm{KL}$, Lucas Jr BD, et al. Double-Blind, Randomized, PlaceboControlled Evaluation of Atropine to Prevent Vasovagal Reaction During Removal of Femoral Arterial Sheaths. Pharmacotherapy: The J Human Pharmacology \& Drug Therapy. 1997; 17(5): 86773.

21- Aktas YY, Karabulut N. The use of cold therapy, music therapy and lidocaine spray for reducing pain and anxiety following chest tube removal. Complement Ther Clin Pract. 2019; 34: 179-84. DOI: 10.1016/j.ctcp.2018.12.001 PMID: 30712725 
22- Shaaban Khalil N. Effect of application of ice pack on reducing pain during the arterial puncture. Clinical Practice. 2017; 14(4). DOI: $10.4172 /$ clinical-practice. 1000115

23- Mehdi Hatami M. The Effect of Cold Compresses on the Comfort of the Patients During Chest Drainage Tube Removal After Cardiac Surgery: a Randomized Clinical Trial. Sci J Hamadan Nurs \& Midwif Faculty. 2018; 26(1): 57-62. DOI: 10.30699/ sjhnmf.26.1.57

24- Akhavan S, Abbasi P. A different look at transradial angiography. Cardiovasc Nurs J. 2016; 5(2): 66-71.

25- Mohammadi N, Pooria A, Yarahmadi S, Tarrahi M, Najafizadeh H, Abbasi P, et al. Effects of cold application on chest tube removal pain in heart surgery patients. Tanaffos. 2018; 17(1): 29.

26- Bikmoradi A, Zafari A, Oshvandi K, Mazdeh M, Roshanaei G. Effect of progressive muscle relaxation on severity of pain in patients with multiple sclerosis: a randomized controlled trial. Hayat, Journal of School of Nursing and Midwifery, Tehran University of Medical Sciences. 2014; 20(1): 26-37.

27- Akbari H, Ghasemi M, Yegani T, Fesharaki MG, Saraei M, Barsam Y, et al. Million Visual Analogue Scale Questionnaire: Validation of the Persian Version. Asian Spine J. 2019; 13(2): 242-7. DOI: 10.31616/asj.2018.0223 PMID: 30481975

28- Abbasi Teshnizi M, Kianinejad A, Gandomkar F. Effect of Applying Ice Bag on Pain Intensity Associated with Chest Tube Removal After Cardiac Surgery. Horizon Med Sci. 2012; 18(3): 109-14.

29- Ertug N, Ulker S. The effect of cold application on pain due to chest tube removal. J Clin Nurs. 2012; 21(5-6): 784-90. DOI: 10.1111/j.1365-2702.2011.03955.x PMID: 22082021

30- Shimaa E. The Effectiveness of Using Ice Application on Vascular Access Site Complication after Cardiac Catheterization. J Nurs \& Health Sci.5(1): 8-16. DOI: 10.9790/1959-05140816

31- Gorji HM, Nesami BM, Ayyasi M, Ghafari R, Yazdani J. Comparison of Ice Packs Application and Relaxation Therapy in Pain Reduction during Chest Tube Removal Following Cardiac Surgery. N Am J Med Sci. 2014; 6(1): 19-24. DOI: 10.4103/19472714.125857 PMID: 24678472

32- Malanga GA, Yan N, Stark J. Mechanisms and efficacy of heat and cold therapies for musculoskeletal injury. Postgrad Med. 2015; 127(1):57-65. DOI: 10.1080/00325481.2015.992719 PMID: 25526231 